\title{
Structural biology for virus research
}

\author{
Yasuyuki Miyazaki', Mikako Fujita ${ }^{2}$, Masako Nomaguchi ${ }^{1}$ and Akio Adachi ${ }^{1 *}$ \\ Department of Microbiology, Institute of Health Biosciences, The University of Tokushima Graduate School, Tokushima, Japan \\ 2 School of Pharmacy, Research Institute for Drug Discovery, Kumamoto University, Kumamoto, Japan \\ *Correspondence: adachi@basic.med.tokushima-u.ac.jp
}

Viruses are strictly dependent on target host cells for their amplification. However, each virus has a unique strategy at each replication step, beginning with entry into the cell, followed by transcription, translation, assembly of viral genome/proteins, and finishing with the cellular release of progeny virions. Extensive studies utilizing bio-structural technology have revealed detailed, bottom line mechanisms of viral replication processes that we virologists need to understand these complex interactions between viruses and host cells. We now know that viral genome/proteins are highly dynamic in nature, and are impressed by their ingeniously organized functionality in hostile host environments.

To characterize viruses as unique genetic entities and pathogenic agents, individual viral components and host factors involved in the virus replication cycle must be thoroughly investigated. Many viral and cellular factors essential for viral replication and pathogenicity have been recently revealed through the efforts of gifted and diligent virologists, and understanding the functional interactions of these viral and host molecules will require an increased use of structural biology and the generation of high-resolution three-dimensional structures. Of note, a number of anti-viral drugs have been generated based on such structural information, and structural characterization of interacting interfaces between virus and host components should reveal potent targets for the design of future specific anti-viral drugs and/or vaccines.

In this Research Topic, a number of structural and molecular biological studies on various viruses by influential researchers have been published as either original research articles, reviews, mini-reviews, or commentary articles. The viruses covered are measles virus (MV), influenza virus, hepatitis $\mathrm{C}$ virus (HCV), hantavirus, murine leukemia virus (MuLV), and human/simian immunodeficiency viruses (HIV/SIVs). General remarks applicable to a wide range of viruses are also included. Consequently, papers comprising this Research Topic on diverse aspects of viral replication will be relevant to many different viruses. Hashiguchi

\section{REFERENCES}

Adachi, S., Adachi, A., and Nomaguchi, M. (2011). Commentary on a new era of investigating 3D structurebased human-virus protein network dynamics. Front. Microbiol. 2:186. doi: 10.3389/fmicb.2011.00186

Arias, J. F., Iwabu, Y., and Tokunaga, K. (2011). Structural basis for antiviral activity of BST-2/tetherin and its viral antagonism. Front. Microbiol. 2:250. doi: 10.3389/fmicb.2011.00250

Binning, J. M., Leung, D. W., and Amarasinghe, G. K. (2012). Aptamers

et al. (2011) review the molecular basis for the interaction of MV hemagglutinin and cellular receptors. Inoue et al. (2011) present a study on the translation of MV nucleocapsid mRNA. Noda (2012) describes a model of native influenza virion morphology. Molecular mechanisms underlying the genesis of infectious HCV have been summarized by Suzuki (2012). Estrada et al. (2011) report the structural analysis of viral membrane glycoprotein Gn from pathogenic and non-pathogenic hantaviruses. Many articles focusing on retroviruses are also presented. Ghanam et al. (2012) review the structural and functional role of the HIV-1 matrix protein for virus assembly. Masuda (2011) focuses on the non-enzymatic functions of HIV-1 integrase and discusses future targeted drug development. Sakuragi (2011) has clarified the morphogenesis of infectious HIV-1 virions and discussed the importance of such research for anti-viral therapy. Comprehensive, informative reviews on cellular anti-viral factors, i.e., APOBEC3 family (against HIV-1) and BST-2/tetherin (against HIV-2, SIV, Ebola virus, and Kaposi's sarcoma-associated herpesvirus), are provided by Kitamura et al. (2011) and Arias et al. (2011) respectively. Seki and Matano (2012) describe viral structure/function (HIV/SIV) and host cytotoxic T lymphocyte responses, while Miyazaki et al. (2011) focus on the structural dynamics of retroviral genome packaging (MuLV, HIV-1, and HIV-2). In a review article, Binning et al. (2012) discuss the potential roles of aptamers in structural virology and in clinical virology, with a commentary by Miyazaki and Fujita (2012). Finally, another commentary on the article dealing with the human/virus protein interaction network is offered by Adachi et al. (2011).

We are proud to present "Structural biology for virus research" as one of the Research Topic in Frontiers in Virology. We believe that all readers should taste the essence and possibility of structural virology in a broad sense. We are optimistic that this Research Topic will provide or re-generate/re-organize strategic insights into the important issues of today's virology.

lular trafficking and targeting to the plasma membrane for virus assembly. Front. Microbiol. 3:55. doi: 10.3389/ fmicb.2012.00055

Hashiguchi, T., Maenaka, K., and Yanagi, Y. (2011). Measles virus hemagglutinin: structural insights into cell entry and measles vaccine. Front Microbiol. 2:247. doi: 10.3389/ fmicb.2011.00247

Inoue, Y., Sato, H., Fujita, K., TsukiyamaKohara, K., Yoneda, M., and Kai, C. (2011). Selective translation of the measles virus nucleocapsid mRNA by La protein. Front. Microbiol. 2:173. doi: 10.3389/fmicb.2011.00173

Kitamura, S., Ode, H., and Iwatani, Y. (2011).Structural features of antiviral APOBEC3 proteins are linked to their functional activities. Front. Microbiol. 2:258. doi: 10.3389/fmicb.2011.00258

Masuda, T. (2011). Non-enzymatic functions of retroviral integrase: the next target for novel anti-HIV drug development. Front. Microbiol. 2:210. doi: 10.3389/fmicb.2011.00210

Miyazaki, Y., and Fujita, M. (2012). Commentary on aptamers for virus 
research. Front. Microbiol. 3:52. doi: 10.3389/fmicb.2012.00052

Miyazaki, Y., Miyake, A., Nomaguchi, M., and Adachi, A. (2011). Structural dynamics of retroviral genome and the packaging. Front. Microbiol.2:264. doi: 10.3389/fmicb.2011.00264

Noda, T. (2012). Native morphology of influenza virions. Front. Microbiol. 2:269. doi: 10.3389/ fmicb.2011.00269
Sakuragi, J. (2011). Morphogenesis of the infectious HIV-1 virion. Front. Microbiol. 2:267. doi: 10.3389/ fmicb.2011.00267

Seki, S., and Matano, T. (2012). CTL escape and viral fitness in HIV/SIV infection. Front. Microbiol. 2:247. doi: 10.3389/ fmicb.2011.00247

Suzuki, T. (2012). Morphogenesis of infectious hepatitis $\mathrm{C}$ virus particles.
Front. Microbiol. 3:38. doi: 10.3389/ fmicb. 2012.00038

Received: 12 February 2012; accepted: 23 February 2012; published online: 13 March 2012.

Citation: Miyazaki Y, Fujita $M$, Nomaguchi $M$ and Adachi A (2012) Structural biology for virus research. Front. Microbio. 3:91. doi: 10.3389/ fmicb.2012.00091
This article was submitted to Frontiers in Virology, a specialty of Frontiers in Microbiology.

Copyright (C) 2012 Miyazaki, Fujita, Nomaguchi and Adachi. This is an openaccess article distributed under the terms of the Creative Commons Attribution Non Commercial License, which permits noncommercial use, distribution, and reproduction in other forums, provided the original authors and source are credited. 